\title{
Selection and Ranking of Low Cost Countries for Outsourcing and Offshoring in the Manufacturing Sector
}

\author{
Rahul Ulhas Pai ${ }^{1,2}$, Sujit Banerji ${ }^{2}$, Jose Arturo Garza-Reyes ${ }^{3}$, \\ Ming Lim ${ }^{3}$, and Vikas Kumar ${ }^{4}$ \\ ${ }^{1}$ Cummins Ltd, Darlington, UK \\ pai.rahul@cummins.com \\ ${ }^{2}$ Warwick Manufacturing Group, The University of Warwick, Coventry, UK \\ S.Banerji@warwick.ac.uk \\ ${ }^{3}$ Centre for Supply Chain Improvement, The University of Derby, Derby, UK \\ $\{$ J . Reyes, M. Lim\} @derby . ac .uk \\ ${ }^{4}$ Dublin City University Business School, Dublin City University, Dublin, ROI \\ vikas.kumar@dcu.ie
}

\begin{abstract}
With the advent of globalisation, there is a need for companies to gain and sustain a competitive advantage. Outsourcing and offshoring are strategies often employed by organisations to sustain and gain such competitive advantage. This paper focuses on evaluating the factors that influence the selection of Low Cost Countries (LCCs) for outsourcing and offshoring. It also ranks a group of seven LCCs to determine the best locations to emigrate manufacturing operations. To do this, the most influential factors for outsourcing and offshoring are identified and weighted based on their importance. Then, these factors are evaluated based on the degree of development in the studied LCCs. The study indicates that Taiwan, Indian and China are the best top options for manufacturing organisations to outsource/offshore their operations.
\end{abstract}

Keywords: Globalisation, Low cost countries, Manufacturing sector, Offshoring, Outsourcing.

\section{Introduction}

In this era of globalisation every organisation is striving hard to be competitive. Competitive advantage can be achieved in a number of ways, for example, by creating technological and product monopolies, providing high quality and/or low cost products, devising aggressive marketing and promotional activities, offering value added services, creating a wide and loyal customer base, etc. In particular, companies are experiencing immense pressure from customers to provide good quality products at reduced costs. At the same time, organisations have to increase their revenues and boost or sustain their profit margins to provide appropriate returns on investment to their shareholders.

One of the initiatives that global companies have undertaken to be competitive and meet the expectations of the customers and shareholders is by developing a sourcing 
strategy that lays emphasis on outsourcing components/products from or offshoring manufacturing operations to Low Cost Countries (LCCs). In recent years, manufacturing companies have identified outsourcing and offshoring to emerging economies as a competitive business strategy to create value for their organisation. In order to sustain and overcome the competitive pressures occurring from globalisation, manufacturing firms, especially in developed countries, look at outsourcing and offshoring to LCCs as a viable option [1]. Globalisation has brought countries closer, thus allowing companies to carry out business not only limited to their home country but also in other parts of the world. Thus, many American and European companies have resorted to outsourcing products and components from vendors in LCCs. Sourcing products from LCCs allows the procuring company to reduce cost on purchased materials and services. For this reason, LCC sourcing has become a strong business trend in the recent years [2-5].

Looking at the increasing trend in outsourcing and offshoring especially to emerging economies, it is of vital importance to understand the factors driving outsourcing and offshoring decisions pertaining to country selection. Country selection plays an important role in outsourcing and offshoring decisions as most of the factors influencing country selection are not in the control of the organisation. The organisation can only evaluate these factors by comparing them with those of other countries and then make the right decision on country selection. Hence this paper focuses on evaluating the factors influencing country selection decisions. After evaluating the factors, the paper rates them against each of the LCCs selected for study. Therefore, the purpose of this paper is to provide a selection and ranking of LCCs for outsourcing and offshoring in the manufacturing sector, and to evaluate the factors affecting the selection and ranking of LCCs for outsourcing and offshoring in the manufacturing sector.

\section{Literature Review on Outsourcing, Offshoring and Low Cost Countries}

According to [6], sourcing can be defined as a process by virtue of which tasks are contracted or delegated to an external or internal agency rather than doing them inhouse. Two dimensions of sourcing are outsourcing and offshoring. Outsourcing refers to the arrangement wherein an organisation contracts or delegates a business process, or a part of it, to an outside entity whereas offshoring implies the transfer or relocation of some of the organisational activities to another country [6]. Berry [7] comments that outsourcing and offshoring are often incorrectly used as interchangeable terms. Researchers differentiate outsourcing and offshoring on the basis of two things: 1) whether the business functions are carried out in-house or they are outsourced, and 2) the geographical location of the business processes to be performed [8]. For example, offshoring takes place when a company transfers jobs which were earlier carried out in its home country to another country, preferably to a LCC. On the other hand, outsourcing is limited to procurement of products or services from a third party service provider or vendor based in the procuring company's home country or abroad. Thus it can be said that offshoring is a subset of outsourcing [7].

There may be numerous reasons for manufacturing organisations to integrate outsourcing or offshoring as part of their overall business strategy. According to [9], 
some of these reasons include: 1) to acquire new skills and a 2) more effective management, 3) to focus on core business functions and products, 4) to avoid capital investment, and 5) to reduce cost. The freeing up of world markets has caused companies to become immensely cost competitive. Thus, cost reduction can arguably be considered the primary reason for manufacturing organisations to seek the "emigration" of their operations to LCCs. In manufacturing terms, Crnlc et al. [10] consider LCCs as those developing countries that posses an strong manufacturing base but where the cost of living and labour is lower than those of developed countries. For the purpose of this paper, the following LCCs were considered due to the relevance and importance they currently present as main choices for outsourcing and offshoring activities: China, India, Thailand, Taiwan, Philippines, Indonesia, and Nigeria.

The intensive cost competition experienced by organisations in the international market has compelled them to concentrate all their efforts on their core competencies and pay special attention on outsourcing and offshoring decisions. As rightly mentioned by [11-12], out of the total production cost of a product, 60 to 70 percent are procurement costs (i.e. the cost of buying the subcomponents from vendors). Thus, it is evident that supply part costs constitute a major portion of the overall cost of the product. Also it can be said that cost reductions obtained from optimisation and improvement in production processes are limited and that cost reduction throughout the supply chain is necessary to stay competitive. Therefore, outsourcing and offshoring decisions have obtained more importance than before and the purchasing/sourcing department that earlier used to be a mere operational business function has now assumed strategic importance. A study conducted by [13] shows that cost savings of $1 \%$ on procured materials increase the profitability of the company by $11 \%$ in the engineering sector.

Global reach and presence enables companies to be competitive by procuring and manufacturing cost effective products from emerging economies. Thus LCCs play a vital role in achieving considerable cost savings [14-15]. Companies have identified the potential of these emerging economies and are exploiting them to reap benefits to stay competitive in the market. LCCs in emerging economies offer excellent sourcing opportunities in the form of cost reduction on procured and manufactured products and potential for sales in the local markets [16-17].

\section{Factors Affecting the Selection of LCCs}

Outsourcing and offshoring decisions are greatly influenced by the selection of the right location. Location refers to the country in which the company plans to outsource or offshore. The decision making process of outsourcing/offshoring to a third party vendor by setting up a subsidiary mostly depends on the attractiveness of countries as sourcing destinations. The attractiveness of these countries keep on changing depending upon the economical, political, cultural, social, technological, etc. environment in that country. The above mentioned factors are pretty dynamic in nature and hence the country attractiveness also keeps on changing. Hence it is necessary to understand the impact of these factors from a long term strategic business perspective [6]. Ample literature is available on Brazil, Russia, India and China, their attractiveness, and the factors influencing their attractiveness as 
outsourcing and offshoring destinations for information technology (IT) and business process outsourcing industries $[6,18]$.

Different frameworks are available that help organisations in exploring the attractiveness of countries for outsourcing and offshoring. One of these frameworks is the Carmel's “oval model” of country selection [19], see Figure 1.

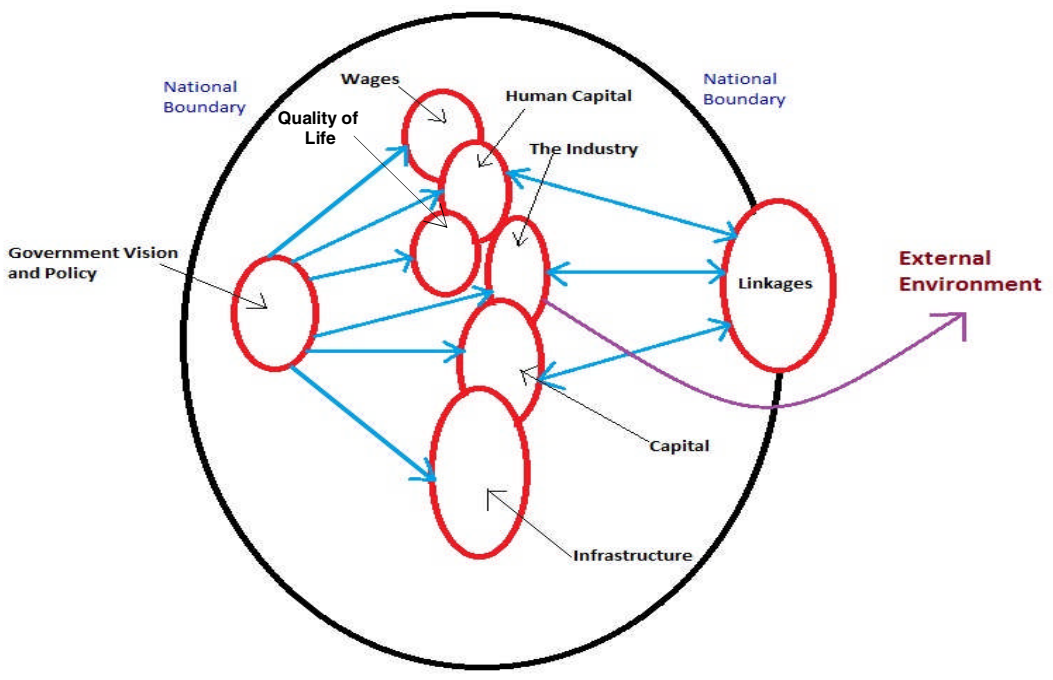

Fig. 1. Carmel's "oval model” of country selection [19]

According to Carmel's model, there are eight factors that lead to the success of nations exploring, particularly IT software. Though these factors are discussed from an IT perspective, they can also be used to explore the factors leading to attractiveness of countries as destinations for outsourcing and offshoring in the manufacturing sector.

A different approach that may be used to determine the attractiveness of countries for outsourcing and offshoring is to consider the factors influencing the competitiveness of a country. The World Economic Forum identifies eleven pillars (see Figure 2), or factors, leading to a country's competitiveness. These factors, according to the World Economic Forum, are also divided into sub-factors that present a more detailed overview of the main eleven pillars. For example, the "Institutions" factor is further divided into five sub-factors that include: 1) intellectual property rights, 2) burden of government regulations, 3) efficiency of legal system, 4) transparency of government policy making, and 5) influence of terrorism on business activities. Similarly, the "Infrastructure" factor is divided into two sub-factors such as 1) quality of overall infrastructure and 2) quality of electricity supply. The rest of the factors are also divided into some sub-factors.

\subsection{Selection of Factors Influencing Country Selection for Outsourcing and Offshoring}

The authors consider that the competitiveness of a country is a key determinant for organisations to select an appropriate country for outsourcing and offshoring. 
However, although the competitiveness of a country stimulates outsourcing/ offshoring activities and attracts foreign direct investment (FDI), the researchers consider that not all the eleven factors have the same importance or consideration while taking outsourcing or offshoring decisions. Hence this paper analyses and discusses the influence of top four factors important from the outsourcing and offshoring decision's point of view. The factors which the authors concentrate on are shown in the Figure 3.

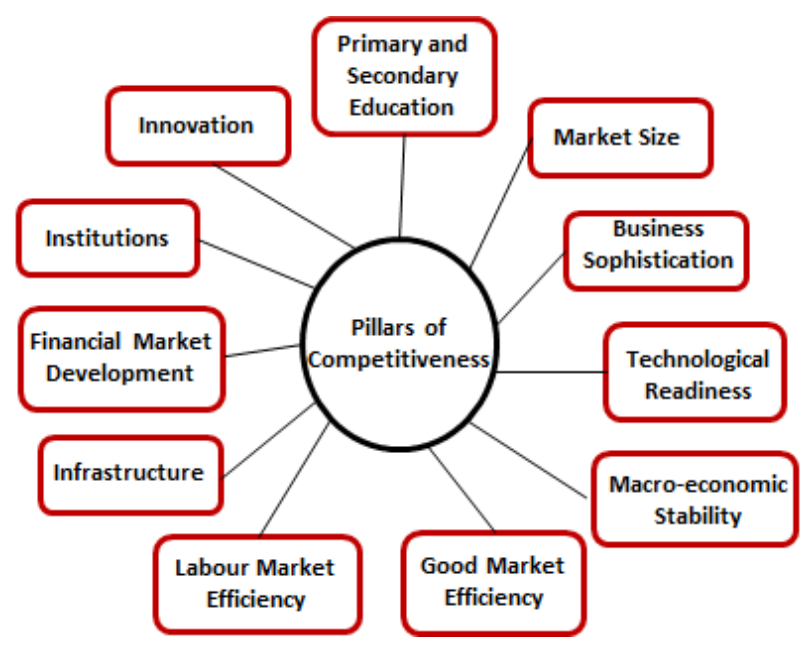

Fig. 2. Pillars of Country Competitiveness

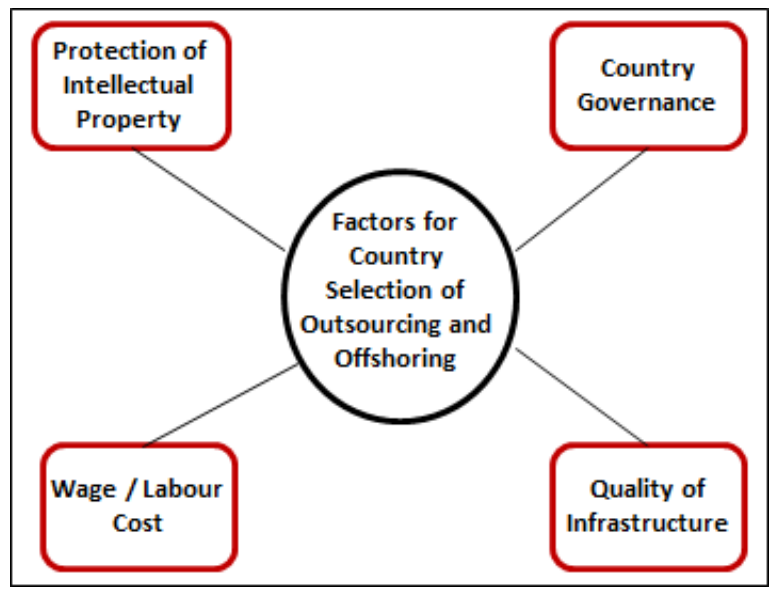

Fig. 3. Factors for country selection for outsourcing and offshoring

The reason behind choosing these four factors for ranking the LCCs studied (i.e. China, India, Thailand, Taiwan, Philippines, Indonesia, and Nigeria) is that, these are not in control of the outsourcing or offshoring organisation. The organisation cannot play a direct role in improving these factors for any country. These are developed 
within the country itself by the governing bodies with a view to facilitate the overall growth of the country and for the betterment of its citizens. As a matter of fact, organisations outsource or offshore in certain countries because they get ready access to these factors in that particular country. Favourable presence of these factors increases the attractiveness of the country towards any outsourcing or offshoring opportunity and FDI.

\subsection{Weighting and Importance of the Factors for Ranking the Countries}

The primary purpose of this paper is to rank the LCCs studied as apt locations for outsourcing or offshoring. In order to do this, the authors weighted the four factors under consideration as per their importance in the outsourcing or offshoring decision making process. Weighting the factors helped to prioritise their influence, thus stressing the importance of each one of them while making outsourcing and offshoring decisions. The factors were weighted on a scale of 10 to 50. A weight of 10 depicted least importance of a particular factor and a weight of 50 represented highest importance of a particular factor for country selection. The weighting scale of 10 to 50 was randomly selected by the authors, just to signify the prominence of the factors. The scale may be modified to suit individual requirements, but the key is to appropriately weight the factors as per their importance in decision making.

After weighting the factors as per their importance, the seven LCCs were individually rated against the four factors, based on the performance of each country in relation to each of the factors. This rating was done on a scale of 1 to 7 . A rating of 1 meant, the country ranks unfavourably in a particular factor and a rating of 7 implied favourable conditions of the factor in that country. The rating assigned was based on the analysis of the individual factors in relation to every country, the extensive literature reviewed made by the first author, and instances from professional experience of the authors.

\section{Protection of Intellectual Property (IP)}

Organisations invest a lot of human and financial resources in research and development. Research and development in the manufacturing sector is necessary for the development of innovative technologies and products. New technologies and products give organisations a competitive edge in the global market, thus strengthening their market position. Hence it is of utmost importance for organisations to safeguard their confidential information, technologies, product designs, etc. from the rest of the world, especially competitors because there is a fear of these getting leaked or illegally copied. This is termed as loss of IP. It is very important for an organisation to safeguard its IP property because, if it accessed and used by others unethically, it deprives the owner of the honorary and monetary benefits. IP can be safeguarded by patenting it with internationally recognised organisations such as USPTO, WIPO, etc. Since it requires a lot of investment for patenting, organisations usually do not resort to this option, unless and until it is a high-tech product, design or technology which is strategically important for a company's survival in the market. Other intellectual property such as part drawings, basic manufacturing process parameters, manufacturing process sheets, costing information, other management data, etc. may not be considered as important, but still play a significant role at operational level. 
IP protection is governed by the law of the country where it has been filed, which has provisions to handle such cases. The legal system of the country should also be sensitive enough to the offence of breach of IP and should have stringent enforcement laws which should be efficient enough to give quick results. Different countries have different laws and regulations for handling IP breach cases. The laws in some countries are efficient while in some others they are not.

Having discussed the importance of IP in detail, it is evident that it is one of the decisive factors for organisations to make outsourcing and offshoring decisions. But in comparison with the other three factors under consideration in this paper, it can be seen that IP protection is predominantly an internal factor due to its governance is within the control of the company to a certain extent. If the outsourcing or offshoring organisations take necessary precautions to protect their IP rights at organisational level, instances of IP breach can be controlled without having to raise the issue to the level of law suit.

Hence on a weighting scale of 10 to 50, IP protection has been given a weight of 20. It is important to remember that this weighting has been done purely on comparative basis with respect to the other three factors. If compared with different assessing factors, the weighting may change depending upon the importance of other factors with respect to IP protection.

\section{Country Governance}

Country governance is an important macro-level factor that influences an organisation's decision about outsourcing and offshoring to a particular country. Governance plays an important role in the economic development of a country because other micro-level factors are directly or indirectly dependent on the policies and regulations formulated by the government of such country. Country governance includes factors like political stability, accountability towards the citizens, formulating policies for political, economical, social, technological, environmental and legal development of the country, efficiency of enforcement of these policies, citizens security, etc. Irrespectively of the type of governance, these factors play an important role in developing the competitiveness of a country.

The seven LCCs considered in this paper are governed differently by their respective governing bodies. Hence the ideology and vision around which the macrolevel policies are made and implemented are also distinct. These seven countries follow distinct political systems and hence operate differently in their own respect. For instance, China follows a communist political system wherein the citizens of the country have little or no role to play in the government selection process. But even then, China has experienced immense economic growth over the past years. This is because the communist party in China is committed towards the country's overall development. Since it does not follow a parliamentary form of government, it can formulate and implement policies without much opposition or debate. Hence the time taken to implement the policies is fast. But this type of governance also has its illeffects such as citizens being unsatisfied with the way in which the country is being currently run, which may lead to a violent revolt to overthrow the current government. This type of incident happened in Thailand in 2010. But China is an exception because the communist type of governance is deeply rooted in the political system of the country. As opposed to China, India is a democratic country and the second 
largest emerging economy after China. India has its share of drawbacks, given the democratic political system it follows. Policy formulation and implementation in India is time consuming since it has to be approved by the other members of the parliament with majority. The two main political parties in the country follow completely different social and religious ideologies, but share similar views about the economic and overall development of the country. The drawback of India's political system is that it is plagued with corruption and bureaucracy. India also faces terrorism threats from its neighbouring country Pakistan along with some cross border issue with China. The other LCCs Philippines, Nigeria, Thailand, Indonesia and Taiwan also have similar advantages and disadvantages in their own governance systems.

On a weighting scale of 10 to 50, country governance has been given a maximum weight of 50 as compared to the other factors. This is because all development actions in any country are driven by its governance efficiency. The economic development of a country immensely depends on its governance. Any corporate policies and regulations are formulated on the lines of governance policies to ensure compliance to the legal system.

\section{Wage / Labour Cost}

There are various reasons behind organisations taking outsourcing and offshoring decisions. These include focus on core competencies, to avoid investment in capital, to get access to world class skills of service providers, etc. But in the real world, the primary reason for any outsourcing or offshoring decision is cost reduction. In the global competitive market, there are persistent pressures by customers to get low cost products at higher quality. With a view to achieve this objective, organisations try to focus on their core competencies by outsourcing or offshoring the non-core functions to a service provider who excels in the same. In a manufacturing industry, 60 to 70 percent of the parts in a product are procured from outside suppliers and the manufacturing company only assembles it and sells it to the customers. In case of manufacturing of engineering products such as automobiles, industrial products, etc. most of the assembly work is labour intense rather an automated. Hence labour wages form an important component of the unit cost of the product.

Countries in the emerging economies offer a low cost environment, predominantly because they have capable workforce abundantly available at low cost as compared to developed countries. Availability of cheap labour gives them a competitive edge over other developed countries. Hence there is a trend in the industry that most manufacturing organisations are sourcing products from or starting new operations in these LCCs.

But this trend in the labour wages seems to be changing over the past few years. This is due to the worldwide uncertain economic conditions which have resulted in unemployment, high inflation rates, etc. Also, due to rapid economic development in the emerging economies, especially in the Asian countries, the standard of living of the people has increased. This has inflated the labour costs further. Also over the past few years there has been a major change in the mentality of the senior management of organisations to not only focus on the product cost, but look at the bigger picture of Total Cost of Ownership (TCO) when making outsourcing and offshoring decisions. Also cost is no more the only decisive factor for making outsourcing and offshoring decisions, but companies look at it from a strategic perspective to develop business 
opportunities in the emerging economies. China and India are the two most populous countries in the world offering an advantage of becoming a huge local market for products being produced in their respective countries. Also most of the manufacturing of electronic products is done in South-East Asian countries like Taiwan, China, Thailand, etc. Asia has become the factory for the world.

Hence owing to the reasons stated above, labour wages have been given a weight factor of 40 as compared to the other three factors. Labour wages have been given a lower weight than country governance because, in most countries the minimum wages to be received by a labourer is fixed by the government and the organisation is liable to comply with this requirement.

\section{Infrastructure}

Infrastructure plays an important role in the development of the manufacturing sector. The development of the manufacturing sector within a country largely depends upon the commitment of the government towards increasing the competitiveness of the country, thus making it an attractive destination for FDI and outsourcing/offshoring. This can be done by having a well developed infrastructure conducive to support business activities in the manufacturing sector. Sound infrastructure includes well developed network of roadways, railways, waterways, airways that can enable logistics support to the manufacturing sector which increases the efficiency of importexport and local trading. Industrial areas are developed at specific locations in a country, where there is ample space available for the construction of large factories. Industrial areas are usually developed aloof from the residential areas so as to minimize the adverse effects such as noise and environmental pollution. Infrastructure is not only limited to efficient network, but it also encompasses the quality and capacity of roads, railways, ports and airports to handle cargo and human traffic.

Infrastructure has been given a weight of 30 on a scale of 10 to 50 based on the comparative importance of this factor with respect to the other three. This factor was weighted lower than country governance and labour cost because, infrastructure development is dependent upon the government policies and budget allocated to its development. Hence if a government has suitable policies and efficient implementation plans it will suffice the purpose of good infrastructure as well. Even though a particular LCC may have good infrastructure, the cost factor overtakes its importance because a company has to make profits to sustain its business and give appropriate returns to its stakeholders.

Table 1 summaries the weight assigned to the four factors identified as critical for the effective selection of LCC for outsourcing and offshoring.

Table 1. Weighting of factors - scale 10 to 50

\begin{tabular}{|c|c|c|}
\hline & Factors affecting outsourcing and offshoring decisions & Weights \\
\hline $\mathbf{1}$ & Intellectual Property Protection & 20 \\
\hline $\mathbf{2}$ & Country Governance & 50 \\
\hline $\mathbf{3}$ & Labour Wages & 40 \\
\hline $\mathbf{4}$ & Infrastructure & 30 \\
\hline
\end{tabular}




\section{$4 \quad$ Rating and Ranking of LCCs}

Based on the discussion carried out in section 3.2, the seven LCCs were rated on a scale of 1 to 7 depending upon the favourable and unfavourable presence, in each country, of the four factors considered in this study. The rating was influenced by a detailed country analysis, the authors' knowledge and professional experience and current political, legal and economic situation and trends in the respective countries.

Table 2 shows the rating of the seven LCCs studied as apt locations for outsourcing and offshoring. According to the rating, Taiwan emerges as the most attractive destination for outsourcing and offshoring in the manufacturing sector with the highest score of 690. Second position is secured by India predominantly due to its democratic governance system and low labour costs. India's score is 670 . China ranks third with a score of 600 , mostly due to its extremely efficient infrastructure that supports the manufacturing sector. Thailand, Indonesia, Philippines and Nigeria ranked in fourth, fifth, sixth and seventh position respectively.

Table 2. Rating of the LCCs studied

\begin{tabular}{|c|c|c|c|c|c|c|c|c|c|c|c|c|c|c|c|c|c|c|}
\hline \multirow{3}{*}{$\begin{array}{l}\text { Factors for } \\
\text { outsourcing } \\
\text { a nd } \\
\text { offhoring } \\
\text { decisions }\end{array}$} & \multirow{3}{*}{$\begin{array}{l}\text { Factor } \\
\text { We ight } \\
\text { (W) }\end{array}$} & \multicolumn{14}{|c|}{ Low Cost Coumtries } & \multirow{3}{*}{$\begin{array}{l}\text { Min } \\
\text { Rate }\end{array}$} & \multirow{3}{*}{$\begin{array}{l}\text { Max } \\
\text { Rate }\end{array}$} & \multirow{3}{*}{$\begin{array}{c}\text { County } \\
\text { Mean }\end{array}$} \\
\hline & & \multicolumn{2}{|c|}{ Philippines } & \multicolumn{2}{|c|}{ Nigeria } & \multicolumn{2}{|c|}{ Thailand } & \multicolumn{2}{|c|}{ India } & \multicolumn{2}{|c|}{ Indone sia } & \multicolumn{2}{|c|}{ China } & \multicolumn{2}{|c|}{ Taiwan } & & & \\
\hline & & $\mathrm{PH}_{2}$ & $\mathrm{PH}_{\mathrm{l}} \mathrm{xW}$ & $\mathrm{NG}_{2}$ & $\mathrm{NG}, \mathrm{xW}$ & $\mathrm{TH}_{3}$ & $\mathrm{TH}_{\mathrm{s}} \mathrm{xW}$ & $\mathrm{ND}_{6}$ & $\mathrm{ND}_{6} \mathrm{xW}$ & NO: & $\mathrm{NNO}_{\mathrm{x}} \mathrm{xW}$ & $\mathrm{CH}_{5}$ & $\mathrm{CH}_{5} \mathrm{xW}$ & $\mathrm{TA}_{6}$ & $\mathrm{TA}_{5} \mathrm{xW}$ & & & \\
\hline IP Protection & 20 & 3 & 60 & 1 & 20 & 4 & 80 & 5 & 100 & 2 & 40 & 5 & 100 & 7 & 140 & \multirow{4}{*}{1} & \multirow{4}{*}{7} & 3.9 \\
\hline $\begin{array}{l}\text { Country } \\
\text { Governance }\end{array}$ & 40 & 2 & 100 & 1 & 50 & 3 & 150 & 5 & 250 & 2 & 100 & 4 & 200 & 6 & 300 & & & 3.3 \\
\hline $\begin{array}{l}\text { Labour } \\
\text { Wages }\end{array}$ & 50 & 4 & 160 & 6 & 240 & 2 & 80 & 5 & 200 & 5 & 200 & 3 & 120 & 1 & 40 & & & 3.7 \\
\hline Infr astr ucture & 30 & 2 & 50 & 1 & 30 & 5 & 150 & 4 & 120 & 3 & 90 & 6 & 180 & 7 & 210 & & & 4.0 \\
\hline Total & & \multicolumn{2}{|r|}{380} & \multicolumn{2}{|c|}{340} & \multicolumn{2}{|c|}{460} & \multicolumn{2}{|r|}{670} & \multicolumn{2}{|r|}{430} & \multicolumn{2}{|r|}{600} & \multicolumn{2}{|c|}{690} & \multicolumn{3}{|c|}{$-1=$} \\
\hline
\end{tabular}

$\mathrm{PH}_{1}=$ Philippines; $\mathrm{NG}_{2}=$ Nigeria; $\mathrm{TH}_{3}=$ Thailand $\mathrm{IND}_{4}=$ India; $\mathrm{INO}_{5}=$ Indonesia; $\mathrm{CH}_{5}=$ China; $\mathrm{TA}_{6}=$ Taiwan

\section{Conclusions}

Outsourcing and offshoring are a key business aspect, important from a strategic view point for organisations. Organisations use outsourcing and offshoring as business model to gain and sustain a long term competitive advantage. When making outsourcing or offshoring decisions, there are various factors that need to be considered, for example, which process or product to outsource, selection of service provider, contract management, etc.

Arguably, the most important factor is that of country selection, because not all factors influencing the selection of an appropriate country are in control of the organisation. An organisation has to evaluate the important factors influencing country selection, based on their outsourcing and offshoring vision.

For the purpose of this study, the authors selected four key factors for country selection that were important for the manufacturing sector. These were: 1) Protection of IP, 2) Country Governance, 3) Labour Wages, and 4) Infrastructure.

Since the countries considered were all LCCs, exhibiting similar positive and negative aspects for the above factors, the authors evaluated and studied the 
prominence and presence of each factor in detail. Based on this and after weighting the factors the LCCs studied were ranked as apt locations for outsourcing and offshoring in the manufacturing sector.

In terms of this study's limitations, the authors selected four factors to consider based on target sector, extensive literature review and personal experience. Different sourcing managers may have different requirements when selecting countries for outsourcing and offshoring. Hence, the selection of factors is greatly influenced by the choice of the person making the outsourcing and offshoring decision. Also the weighting of factors is influenced by the involvement of a human aspect, because different sourcing managers may weight the same factors differently as per their outsourcing objectives. In addition, the scope of this study is limited to the manufacturing sector only. Hence the selection of the factors and its analysis and discussions are focused on this sector only. For example, the infrastructure required for IT sector may be completely different from that of manufacturing sector.

Further research can be carried out on this topic by undertaking a real case scenario in an outsourcing company, wherein the practical implications of factors on country selection can be explored. Also, future work on this topic can be done by selecting a different sector such as IT, fast moving customer goods, etc. and analysing the factors influencing country selection pertaining to that particular sector.

\section{References}

1. Javalgi, R., Dixit, A., Scherer, R.: Outsourcing to Emerging Markets: Theoretical Perspectives and Policy Implications. Journal of International Management 15(2), 156-168 (2009)

2. Byrne, P.: Global Sourcing: Opportunities and Approaches for the 21st Century. Logistics Management 44(1), 27-28 (2005)

3. Matteo, M.: Sourcing in China. Chinese Business Review, 30-54 (September-October 2003)

4. Fang, T., Axelsson, B.: Strategic Change towards Global Sourcing: Developing Sourcing Capabilities. John Wiley \& Sons, Chichester (2005)

5. Trent, R., Monczka, R.: Achieving Excellence in Global Sourcing. MIT Sloan Management Review, 24-32 (October 2005)

6. Oshri, I., Kotlarsky, J., Willcocks, L.: The Handbook of Global Outsourcing and Offshoring. Palgrave Macmillan, Hampshire (2009)

7. Berry, J.: Offshoring Opportunities: Strategies and Tactics for Global Competitiveness. John Wiley \& Sons, New Jersey (2006)

8. Domberger, S.: The Contracting Organizations: A Strategic Guide to Outsourcing. Oxford University Press, Oxford (1998)

9. Brown, D., Wilson, S.: The Black Book of Outsourcing: How to Manage the Changes, Challenges and Opportunities. John Wiley \& Sons, New Jersey (2005)

10. Crnlc, F., Kleemann, U., Selder, C.: Low Cost Country Sourcing can benefit a company's bottom line, http: / / www . gregbrennan. com/pdfs / IBM $\% 20$ Low 20 Cost\% 20Country20Sourcing .pdf

11. Chapman, T., Demsey, J., Ramdsdell, G., Reopel, M.: Purchasing - No Time for Long Rangers. The McKinsey Quarterly, 30-40 (May 1997) 
12. Heberling, M., Carter, J., Hoagland, J.: An Investigation of Purchases by American Business and Governments. International Journal of Purchasing and Materials Management 28(4), 39-45 (1992)

13. Bain and Company: Einkaufsstrategien - Herausforderungen für Top Manager, http: / / www.bain.com/bainweb/PDFs / cms / Public/Munich_Results_ Einkaufsstrategien_Herausforderungen.pdf

14. Fitzgerald, K.: Big Savings, But Lost of Risk. Supply Chain Management Review 9(9), 16-20 (2005)

15. Hemerling, J., Lee, D.: Sourcing from China - Lessons from the Leaders. Boston Consulting Group, Boston (2007)

16. Vlcek, J.: Risk Management for Buisness with Low Cost Countries (LCC). European Centre for Research in Purchasing and Supply, Vienna (2006)

17. Piontek, J.: Global Sourcing. R. Oldenbourgh, Munich (1997)

18. Kobayashi-Hillary, M.: Building a Future with BRICs - The Next Decade for Offshoring. Springer, London (2008)

19. Carmel, E.: The New Software Exporting Nations: Success Factors. The Electronic Journal of Information Systems in Developing Countries 13(4), 1-12 (2003) 